\title{
Abbuddhassa Kale: A Time of Godlessness
}

\begin{abstract}
This paper examines the moral tropes through which state employees interact with their clients. Based on ethnographic field work conducted over a period of one year during 2007/2008 in a Probation and Child Care Services Unit in Sri Lanka the paper argues that the moral positions of state employees is rooted within a Sinhala Buddhist nationalist identity. These moral positions are explored particularly in terms of their disposition towards girls and women. The paper examines the ways in which these moralities are expressed have particular outcomes for the girls and women who are clients of the Probation and Child Care Services. It shows how Probation Officers assessed their clients' experiences and decided on interventions based on ideas regarding the respectability and virtue of girls and women. The paper goes on to argue that the public enactment and discussion of what it means to be culturally and morally grounded is a means of expressing the particular subjectivities and positions of these particular state employees. These identities are also linked to the ambiguities faced by the mostly middle class state employees in having to differentiate themselves from their class inferiors as well as their class superiors. The paper also shows that state employees resort to moral frameworks to respond to their clients' difficulties in the face of inadequate resources to effectively deal with the complex issues faced by their clients.
\end{abstract}

Keywords: Morality, Nationalism, Culture, Respectability, Surveillance, Middle-class 


\section{Introduction}

This paper is based on ethnographic field work conducted over a period of one year during 2007/2008 in a Probation and Child Care Services Unit (hereafter referred to as Probation Unit) in Sri Lanka ${ }^{1}$. This paper examines the moral tropes through which staff at the Probation Unit understood and explained their clients' experiences. It also explores why the moral positions that the staff took when discussing their clients' experiences implicitly contained a commentary on cultural identity. The way in which Probation Unit staff discussed the morality of their clients suggested that being moral also meant being culturally rooted and grounded. This paper explores why Probation Unit staff used morality as a way of explaining and understanding their clients' experiences and why in their idioms being moral was so often equated with being culturally rooted. This paper also discusses how morality is enacted very much as part of a public discussion: that is, working out what is moral or not is understood through discussing the behaviour of others and individual morality is expressed and measured through the capacity of the person to judge the morality of others.

\section{The Department of Probation and Child Care Services (DPCCS)}

The Department of Probation and Child Care Services (DPCCS) was established in 1956 and the subject was devolved to provincial governments in 1987. Currently, each of the 9 provinces in Sri Lanka has a DPCCS with several Probation and Child Care Services Units functioning under the Department located in each district in the province. Since the work of the DPCCS is closely linked with that of the judicial system, the units are established in various judicial divisions and in close proximity to the courts. In the district where I did my field work, there were 2 such Units.

When the DPCCS was first established, it reflected changing attitudes to the treatment and prevention of crime and specifically what was known as 'juvenile delinquency'. The prevailing idea at the time was that criminals and juveniles in particular needed to be rehabilitated rather than punished. After much debate and discussion, legislation that provided the legal framework for the DPCCS was introduced in 1939 although the setting up of the DPCCS was delayed by several years. The DPCCS is primarily responsible for the care and protection of children who are "orphaned, destitute or abandoned" (Children and Young Persons' Ordinance, Act No 48 of 1939). Additionally, it manages several institutions for the rehabilitation and reform of 'juvenile delinquents'. It is also responsible for supervising residential institutions for children run by voluntary organisations and for managing local and international adoptions. After devolution in 1987, all the responsibilities of the DPCCS were devolved to provincial DPCCS except the formulation of national policies and processing international adoptions which are under the purview of the DPCCS which functions under the central government.

When the DPCCS was established, the main problem it was expected to deal with was juvenile justice and especially the problem of male juveniles who were in conflict with the law. However, although the procedures governing the DPCCS continue today as they were in 1956, the problems they deal with today are not confined to male juveniles or even primarily to juvenile justice. Records in the Probation Unit, where I conducted my research show that the majority of cases they currently deal with are of children in need of care and protection rather than children in conflict with the law. Many of the cases are recorded as incidents of abuse, including sexual abuse. Another change is that the case load, unlike in the past, tilts increasingly in the direction of girls rather than boys.

\footnotetext{
IIn order to protect the identities of the staff and their clients, the location of the district is not revealed.
} 


\section{The Probation Unit Staff}

Each Probation Unit has a Probation Officer in Charge, (POIC) with a senior Probation Officer (PO) in the Provincial DPCCS. All staff reported to the Commissioner of Probation and Child Care Services who is appointed from the Sri Lanka Administrative Service, the highest level within the civil service. Apart from the POIC, there were five Probation Officers, two Development Assistants (DAs), an Administrative Assistant and an Office Labourer working in the Probation Unit where I was located. The POs were responsible for all legal and investigative work while the DAs did monitoring of day care centres, assisting the POs with investigations and other non-legal work that the POIC assigned to them.

All the staff in the Probation Unit were graduates from state universities and they had all attended rural state schools for their secondary education. The POIC had an external degree in the Arts from the Vidyodaya University2 ${ }^{2}$ formerly a Buddhist Pirivena (Buddhist centre of learning). PO Mrs Jayaweera had a degree from Kelaniya University, formerly Vidyalankara Pirivena (another former Buddhist centre of learning). PO Mrs Kularatne had a Diploma in Social Work from the School of Social Work. The younger staff was all appointed through the Graduate Employment Schemes and were Arts and Commerce graduates from local universities.

Socio-economically, the staff of the Probation Unit came from rural, Sinhala-speaking Buddhist backgrounds. Some of the staff owned small plots of land and engaged in various types of cultivation to supplement their rather meagre government salaries. For instance, DA Ajit's family had paddy land, the POIC and PO Mrs Jayaweera owned small plots of tea, DA Nimal grew vegetables and PO Ananda had a small plot of land on which he was growing cash crops. While none of the staff were economically struggling, neither were they financially secure. The battle to manage their finances was a common topic of discussion, especially for PO Ananda who was building a house. DA Ajit who was planning to get married in the near future often complained about the financial difficulties he was facing with regard to meeting his wedding expenses. However, as employees of the public or government sector, Probation Unit staff had a certain status in the community and were considered persons of some authority and respectability.

\section{The Moral Crisis}

The staff at the Probation Unit often described society as being in a state of moral crisis or breakdown. The increasing numbers of child abuse cases, especially cases of sexual abuse, domestic violence, rising rates of divorce, the ineptness of senior officers, the corruption of politicians, the lack of support and resources to do their work, the lack of appreciation and respect for government officers; all of these things were viewed as evidence of a state of moral crisis, both within and outside the Probation Unit. But it was the often horrific and emotionally wrenching work that they dealt with on a daily basis that provoked the most intense discussions at the office regarding the state of morality in society. The POIC had a saying that reflected her views regarding how times had changed: "Issara hora væda. Dæn balu væda" (In the past people stole things. Now they do perverted things), suggesting that there was a qualitative difference to the kinds of issues with which the Probation Unit dealt. Whereas in the past, they had dealt more with petty theft and misdemeanours, the cases they were dealing with now according to the POIC were increasingly in the category of balu væda, falling more into the realms of "perversions."

In a conversation I had with PO Ananda about the type of cases they handled at the Probation Unit, he had this to say:

2Vidyodaya and Vidyalankara Pirivenas became the University of Sri Jayawardenapura and the University of Kelaniya respectively. Initially headed by Buddhist monks and admitting only male students, they gradually started admitting female students and are now secular universities although both have strong Buddhist Studies traditions. 


\begin{abstract}
These days there is general decay in morality (sadacaraya pirihila) among people. It is mainly because of the influence of the media and because there is no proper leadership. The media is slowly destroying our culture. What is being promoted is individualism and materialism: people want instant gratification. We need another Dharmapala again.
\end{abstract}

PO Ananda's words summarised the general opinion in the Probation Unit: that today's society was marked by the degeneration of morals as a result of the values of individualism and materialism that were being promoted primarily by the media. Individualism and materialism were seen as foreign to the moral values that had shaped local culture in the past; they were associated with "modern" values that were destroying local culture. PO Ananda's comment linking the decline in morality to materialism was significant in that it suggested concerns regarding changes to the social structures being wrought by changing economic policies, social aspirations and social practices. By invoking Dharmapala, the Buddhist revivalist, PO Ananda had also touched on another popular theme: the need for a strong leader who could revive "traditional" values and stem the rot that had set in as a result of people forgetting their roots, indigenous morals and values.

Liechty (2002) has argued that the middle class is constantly engaged in negotiating and renegotiating ideas, values and embodied behaviour. Positioned between the "ignorant" lower classes and the "morally depraved" and "culturally alienated" upper classes, the middle class occupies an extraordinarily complex cultural space. While very much a part of the changes that the globalised economy has wrought upon postcolonial states, they are also the most affected by the insecurities brought upon by those changes. For instance, while employment in the state sector is no longer the most obvious means of securing social status and mobility, employment opportunities in other sectors continue to be limited for those who lack the requisite social connections, language skills and appropriate "private sector" cultural traits (National Policy on Youth Employment 2006). Those who do obtain state sector employment are all too conscious of the low salaries and the declining prestige associated with the public sector. Yet, employment in the public sector remains an aspiration for many young graduates and their families from the national universities. There was still a certain degree of respectability and social status associated with state employment which compensated for the low salaries and challenges to its prestige. In the community, a person with a government job was regarded as an educated person - a person with authority.

This position of respectability and authority was what set Probation Unit staff apart from their clients. The staff often described the problems faced by their clients as stemming from moral ambiguity, of not being able to, or not knowing how to, distinguish between right and wrong. This ambiguity was often attributed by the staff to the lack of moral and spiritual values. Staff often said that people were no longer taught right from wrong. There was no proper inculcation of the correct moral values. This was usually attributed to declining standards in the education system as well as a breakdown in traditional family structures which was seen as a feature of modern life.

The cases they dealt with often served as reminders of the dangers of this moral ambiguity especially of modernity. PO Mrs.Kularatne related to me how she discussed the cases she handled with her own teenage daughter, especially those that involved girls of her daughter's age in order to teach her the dangers of modern society. At the same time, the younger, unmarried staff in the office was warned not to become too cynical and disappointed with life as a result of the often harrowing stories we heard in the office. What was evident, however, was that the cases that the Probation Unit staff dealt with provided an opportunity or created a space for discussing and articulating appropriate moral and ethical norms and behaviour. 
Recent anthropological work on morality has dwelt at length on reasons why anthropology has difficulties distinguishing between morals and culture (Laidlaw 2002; Zigon 2007, 2009). This is attributed to the Durkheimian tradition of seeing all normative social action as moral (Laidlaw 2002; Robbins 2007). For Laidlaw, using Foucault's notion of freedom, what constitutes the moral are the things that people do reflectively (Laidlaw 2002). Similarly, Zigon distinguishes between ethics and morals by stating that the ability to be unconsciously moral most of the time is what allows people to be social beings. When people have to stop and consider how to be moral, he describes these as ethical moments (Zigon 2007, 2009). For Zigon, these ethical moments happen when there are "breakdowns" similar to what Foucault (2000) calls problematisation. It occurs when an event or person forces an individual to "consciously reflect upon the appropriate ethical response" (Zigon 2009:262). According to Zigon, these ethical moments are creative since new moral personhoods and new moral worlds are being created through this process. So, in this sense, they also present moments of freedom and choice. Zigon asserts that ethics is a "tactic performed in response to the ethical demand of the moral breakdown to return to the unreflective moral dispositions of everydayness" (2007:139) but that this process alters, even slightly, the unreflective moral dispositions and people's way of "being-in-the-world" (Zigon 2007:138). Because the conscious work of ethics allows a return to the unreflective and unconscious state of morality (even if it is somewhat altered), ethics needs to be performed regularly if there is to be such a morality.

What interests me is the ways in which morality and culture were discussed almost interchangeably at the Probation Unit. Was it because the events in their clients' lives forced the Probation Unit staff to consciously reflect on their own everyday moral dispositions and hence their culture? Were these moments of "moral breakdown," to use Zigon's term, when the Probation Unit staff were able to exercise a certain freedom, choice and reflexivity regarding their moral dispositions and culture? Or were they opportunities for the staff to assert their moral and cultural personhoods? If so, why was this very public assertion of their moral and cultural personhoods such an important factor in their interactions with one another? Are these social performances of identity? And finally, how were their moral and cultural personhoods historically and socially situated?

Zigon identifies three interrelated aspects of morality: those of the institutional, of public discourse and of embodied dispositions (Zigon 2007). At the Probation Unit, these three aspects were almost indistinct. It was the explicitly public nature of morality that I found most intriguing. What I explore in this paper is whether this notion of "moral breakdown" that is expressed at the Probation Unit is linked to the ambiguity of the social position occupied by the middle class. This suggests that the collective assertion of a shared moral space is somewhat different to the ethical practice that Zigon refers to which he analyses as an attempt to return to people's "unreflective moral dispositions". I will discuss these questions in this paper, especially in relation to what was considered the breakdown of the normative moral dispositions of women and girls.

\section{The Staff as Advisors and Moral Guides}

The work of the Probation Unit, linked as it was to issues relating to children and families, provided many opportunities for discussion and reflection on certain notions that were considered essential for the "proper" functioning of society. The family was considered the basic unit of society and children a symbol of innocence as well as of the future. The work that the staff had to do on a daily basis suggested that the family as well as the innocence of children was at risk, thus weakening both the foundation and the future of society. The staff considered themselves to be in a position where they could protect both of these and thus saw instilling particular values, dispensing advice and giving instructions regarding people's morals and behaviour as an integral part of their work. 
Just as Anagarika Dharmapala, the Sinhala Buddhist nationalist leader, passed judgement on his fellow citizens by commenting on their clothes, manners and customs, the staff at the Probation Unit did not hesitate to pass judgement on the behaviour, demeanour and conduct of their clients. Given the nature of their job, which was to assess and make recommendations on how to rehabilitate or reform those who had violated the law or those who had been victims of crimes, the fact that they made these judgements is not at all surprising. Furthermore, the majority of the incidents that they were dealing with involved actions that were condemned by society as deviant or immoral. Some of the cases drew considerable media attention and were often talked of in the media as examples of the depravity and horror that exists in modern society.

The staff at the Probation Unit felt that part of their responsibility therefore in dealing with clients was to instruct them on proper and right behaviour, conduct and values. That many of the problems besetting their clients were due to their not knowing, or contravening, proper ways of behaviour and conduct was something of which members of the staff were convinced. There were differences of opinions among the staff regarding what was "proper" and "good", and many discussions in the office about the more controversial cases they handled. During tea breaks and lunch time, for example, the staff often discussed the cases that they were handling, voicing opinions about their clients' behaviour and analysing the motivations for their clients' actions. Sometimes these discussions led to conversations about the state of morality in society, the lack of respect for traditional values, and the harmful influence of the media, especially on children.

The POs were expected to have close relationships with their clients and often were in contact with their clients over a period of several years during which they were expected to supervise their clients who had been directed by courts for probation or for rehabilitation. Thus, the service that the Probation Unit provided was considered different from all other types of government services. The staff saw themselves as having a special role in the lives of their clients: one that was unique to the service that they provided, as those responsible for the reform and rehabilitation of their clients. Their clients had come before them because they had strayed from acceptable norms of behaviour and it was their responsibility to see that such incidents did not recur. PO Mrs. Kularatne described the role of the PO in the following way:

We hold very sensitive positions. We are like 'dukgannarala'

(those who listen to tragedies). We have to scold when necessary and listen when necessary. We have to strengthen people and at the right time advise them. Not everybody can do this.

The clients did not seem to resent or to be surprised at the extent to which the POs became involved in the intimate details of their lives. They accepted it as part of the process of dealing with the Probation Services. Very often the clients who came to see them, especially the children, went down on their knees and worshipped the staff members as they were leaving. There were even occasions when the POs reminded them to "worship" them in this manner as part of their efforts to inculcate "proper" values among their clients.

Sometimes PO Ananda would describe his role as that of a "counsellor". Describing one of his "successful" cases, he explained how he was particularly happy about the outcome of this case because he was able to make sure that a family on the verge of splitting up was kept together. He said the parents had been considering divorce but that he was able to persuade them to reconsider their decision and to stay together for the sake of the children. He had told them that, like seeds that grow into big trees that provide shade and comfort to so many human beings, children had the potential to become useful and important people in society. He had told the parents that it was their duty to ensure that children were provided with the right environment (in this case, a stable family) within which they could grow up to realise 
the potential in them. According to him, as a result of his advice, the parents had decided to stay together for the sake of the children.

\section{The "Respectable" Sinhala Buddhist Identity}

Respectability was a term that I heard quite often in the Probation Unit. It was talked about in terms of those who are being brought up without the requisite læajja-baya (literally, "shame-fear") or the problems that are caused as a result of women and young girls not having læjja-baya. It was implied that women and girls who had the proper degree of læjjabaya would not be susceptible to the kind of calamities experienced by those that the Probation Unit dealt with.

Respectability has been a central theme in the construction of the ideal Sinhala woman and man. This was particularly important in relation to the ideal Sinhala woman. Malathi de Alwis (1997) has analysed how the Sinhala practice of lajja-baya, which she glosses as respectability, restrains women's lives by placing them under surveillance and requiring them to guard against being shamed or ridiculed as lacking in lxjja-baya.

The Gihi Vinaya (or "Code for the Laity"), written by Angarika Dharmapala, who was invoked by PO Ananda, provided detailed rules for proper behaviour based on Western notions of propriety, while proscribing the "crudities" of Sinhala peasant behaviour. This reflected Dharmapala's own missionary school education and his familiarity with Western culture (Obeyesekere 1997; Wickramasinghe 2006). Dharmapala's Gihi Vinaya had a total of 200 rules under 22 headings, which ranged from the manner of eating food ( 25 rules) to domestic ceremonies (1 rule). The most number of rules (35) were reserved for the conduct of women (Obeyesekere 1997). These included rules about how they should dress, keep their households, maintain personal cleanliness, and conduct relationships with children and servants (de Mel 2001). According to Obeyesekere, these rules were aimed at the Sinhala intelligentsia and many of the proscriptions detailed in the rules are on behaviour associated with peasants and the lower classes such as betel chewing, the use of impolite forms of address and "bad" eating and lavatory habits. Ironically, many of the rules were informed by Western notions of propriety and good behaviour including the correct manner of using the fork and spoon and the use of toilet paper. Dharmapala, while claiming to reject Western culture, according to Obeyesekere, combined at the same time Protestant and Western norms in constructing a pure and ideal Sinhala way of life (Obeyesekere 1997). A reading of some of Dharmapala's texts suggests that his vitriolic critiques of Western culture and of locals who imitate Western culture were also attempts to instil pride in a Sinhala identity, which he believed was lacking due to Sinhala people's blind belief in the superiority of European cultures. Dharmapala's attacks were directed at those who felt that local culture was inferior and who were ashamed of their Sinhala identity. His preoccupation was with constructing an identity for Sinhala Buddhists, and instilling a sense of pride in them; to borrow from the very cultures he was critiquing was not so problematic since his purpose was not so much to reject Western culture as to construct a modern Sinhala Buddhist identity.

The efforts to instil pride in this new Sinhala identity were evident in the literature and theatre during this time of cultural and religious revival. The novels of Piyadasa Sirisena, one of Dharmapala's close associates, celebrated the lives of men and women who took pride in the ancient wisdom and had a knowledge of Eastern cultures and religion. His heroes and heroines were those who triumphed in life by demonstrating the superiority of Eastern culture in debates with Christian missionaries and "unenlightened" locals who had uncritically embraced the culture of their colonial rulers. Sirisena's novels make constant references to the ancient Sinhala Buddhist civilisation and the fact that many aspects of what is considered modern in Western culture existed in indigenous culture when the West was still in a barbaric phase. Amunugama(1997) states that Sirisena's novels were rejoinders to Christian novels that existed at the time in which Christian families were depicted as blessed 
while the Buddhist families were accursed and where Buddhists gained happiness only after their conversion to Christianity (Amunugama 1997).

John de Silva, considered the founding father of Sinhala theatre, was also part of this cultural revivalism. Neloufer de Mel (2001) has examined the portrayals of the ideal Sinhala woman in his theatre productions. She describes how the chaste and dutiful ideal woman is contrasted with women who have come under the influence of Western culture. In de Silva's productions too, the contradictions of portraying the ideal woman who is modern yet rooted in Sinhala Buddhist tradition are present, where women are educated yet respectful of indigenous traditions and mindful of their domestic duties (de Mel 2001).

For the nationalists at the turn of the $20^{\text {th }}$ century, women needed to be modernised only so far as to ensure that they were suitable partners for the modern Sinhala Buddhist man. Very often in the attacks on those who imitated European culture, it was the female who was criticised and parodied. Women, who wore European clothes, drank alcohol and attended society dances were inevitably portrayed as sexually promiscuous and extravagant. They were usually portrayed as the cause of the downfall and destruction of their families. The contrast was the sober, domesticated and demure woman brought up in the Eastern tradition.

Partha Chatterjee $(1989,1993)$ has described how post-colonial nationalist ideology separated the domain of culture into two areas: the material and the spiritual. The material, which was dominated by Western civilisation, contained science, technology and modern forms of state craft and economic organisation. The spiritual realm was dominated by the Eastern civilisations and contained the essential aspects that mark the spiritual distinctiveness of Eastern cultures. Chatterjee has argued that Indian nationalists maintained this cultural distinctiveness in order to borrow selectively from the material advances of Western civilisation without losing their identity. He describes how this separation of the material and the spiritual maps on to the separation of the external world from the internal home. The external world is material and the domain of the male, whereas the spiritual essence is represented in the internal world, the home, by the woman. Nationalism dealt with the question of women through this separation; various strategies were used to reconcile the needs of modernity (education, progress, economic rationalisation) with the need to maintain the spiritual essence of the distinctive cultures. Thus, women had to be both modern and bearers of this cultural essence. Their dress, their demeanour, their religiosity; all the visible markers of their femininity were strictly enforced. Feminist theorists have critiqued Chatterjee for erasing women's agency in this theorisation and have argued that the boundary between the private and public is much more porous than envisaged by Chatterjee (de Mel 2001; de Alwis 1995). As pointed out by de Alwis, women's "spirituality" or, as she prefers to call it, "respectability" is also subject to counter-discourses of sexualisation, especially if women are in the public gaze (deAlwis 1995). Nevertheless, the idea of selectively borrowing in order to construct an "authentic" national identity, and the way in which that identity is centred on the purity of women, remains useful for understanding how nationalists reconciled the sometimes contradictory impulses with which they constructed national identity and traditional culture in their representations of the nationalist woman.

The influence of these religious and cultural revivalist movements has been significant in producing the values that shaped notions of respectability, sexual morality and family life among the Sinhala middle class, especially with regard to the norms that governed the behaviour of women and girls. While Anagarika Dharmapala's influence among the bourgeois class that he represented and critiqued was somewhat muted, especially during his own lifetime, the political changes that have taken place since independence, and the hardening of ethnic identities, has led to a revival of his work. Thus, his battles against the colonial rulers and their local collaborators in constructing and protecting a Sinhala Buddhist identity are taken as examples of the kind of leadership that is required currently as well. 
The strongest adherents of Dharmapala more recently have been drawn from the Sinhalaspeaking intelligentsia. They belong to the group who led the political changes that took place in 1956 in Sri Lanka, such as the introduction of the "Sinhala Only" language policy, and more recently, have been at the forefront of struggles to protect the nation against separatism and cultural dissolution.

At the same time, the type of Sinhala Buddhist identity championed by Dharmapala and other nationalist leaders provided a means for the Sinhala middle class of asserting their power against the social, political and economic dominance of the Westernised upper class and also to distinguish themselves from the crudities of the "lower classes". That the Sinhala Buddhist identity and culture that Anagarika Dharmapala and other nationalist leaders fought to protect is again perceived by this group to be under threat is evident in the contemporary revival of Dharmapla and his philosophy. According to this viewpoint, while the colonialist powers that Dharmapala fought are no more, a new type of threat is still prevalent in the form of the economic, political and cultural imperialism of the West. The local collaborators in this new form of imperialism are also once again seen as the Westernised elites and (inter)national agencies such as NGOs (Non-Governmental Organizations) in which they work. At the same time, the lower classes need to be educated and when necessary even scolded in order to make them adopt attitudes and behaviours more acceptable to the dominant class.

\section{Confronting the "Moral Decay" of Society}

The valorisation of a past Sinhala Buddhist civilisation, respect for "tradition", and nostalgic reminiscences of a more "innocent" past framed the critiques that the Probation Unit staff members had of modern society. The era of economic liberalisation, beginning with the change of government in1977, was sometimes the reference point for when this deterioration had begun. Economic liberalisation was blamed for introducing consumerism and a materialistic culture, which was seen as leading to the deterioration of traditional values and way of life. These views that were expressed by the Probation Unit staff were also evident in some of the Sinhala media. In a radio programme on Universal Children's Day in 2007, I heard speaker after speaker blame materialism and consumerism for a range of evils from bad nutritional habits among children to incest. Mainly mothers were blamed for this: according to the speakers, mothers who selfishly pursued material wealth did not have adequate time to prepare nutritious meals for their children, help them with their schoolwork and also left children unprotected from alcoholic fathers and the influence of unsavoury friends. The material basis of these problems, such as increasing poverty that forced women to leave their families for paid work, was never mentioned by any of the speakers. Rather, the desire to seek paid work was seen in terms of greed and materialism driving women even to place their children at risk. The return to sampradayan (traditional values) and the commitment to protect sanskrutiya (culture) were thus seen as the panacea for most problems facing modern society.

It was when dealing with the cases involving child abuse and domestic violence, which appear to be increasing in numbers (at least in terms of media coverage) that the staff responded to a range of issues that gave rise to intense discussions regarding the moral degeneration of modern society. In recent times, both legal reforms to the penal code in 1995 which enhanced penalties for existing offences as well as identifying new ones and increased publicity and "awareness raising programmes" have led to more reporting of cases to the police and even to the Probation Unit. Some of the cases that the staff dealt with were quite horrific, including cases of incest where fathers and brothers had raped daughters and sisters, cases of statutory rape involving very young children, cases that involved teenage girls who had run off with their boyfriends who were teenagers themselves, and some cases of Buddhist monks who were accused of sexual abuse. In some of these cases, the usual sexual taboos and norms had been violated and these were what disturbed the staff the most. 
Handling the complexities of these cases was made all the more difficult by the limited resources and options that the staff had at their disposal. While they were unequivocal in their condemnation of the offender, dealing with the offender (unless he or she was under 16 years) was usually outside their sphere of responsibility since the police and judiciary were responsible for the prosecution of these cases. The victim was more directly their responsibility since the Social Report that they submitted to court determined what actions should be taken on their behalf.

According to Sri Lankan law, sex with a girl under the age of 16 years is statutory rape. Many of the cases the POs dealt with involved teenagers running away from parental wrath against "unsuitable" love affairs. When apprehended by the police, the girl would be first subjected to a medical examination in order to ascertain if the charge against the boyfriend was rape (if the girl was under 16 years), sexual abuse (if the girl was over 16 years), or merely "forcible removal from legal guardian". In cases involving under-age girls especially, the cases usually came to the attention of the police and Probation Department because the family of the girl (most often) had made a complaint to the police that the girl had been abducted.

According to the POs, they had sometimes dealt with cases in which a girl had accused an uncle or even father or brother of rape in order to protect her boyfriend and to avoid admitting to a forbidden romantic relationship. As a result, the staff often entertained doubts when such cases came their way as to the veracity of the victim's story, especially if a close relative was involved. In such instances, the girl would be subjected to intense interrogation in order to ascertain the "true" facts of the case. However, the more intense deliberations revolved around what to do with the girl involved. While there were a couple of children's homes for sexually abused girls in the province, including ones which were willing to take pregnant teenagers and teenage single mothers, POs were somewhat reluctant to institutionalize these girls, partly as a result of a strong policy directive from the central government discouraging institutionalisation and partly as a result of these homes being overcrowded. POs were also quite critical of conditions in these institutions, often complaining that they were badly managed, poorly resourced and run by unscrupulous and untrained personnel. But POs were also hesitant to allow the girls to return to their homes because they felt that it was something wrong in the girl's home that prompted the incident in the first place: either lack of care by parents, or being in an "immoral" environment, or under the "bad influence" of friends and/or family. They also considered that the girls' lives had been ruined by such an incident and considered it impossible for the girls to return to normal life again. However, given the limited resources that were available to the Probation Unit and the often complex situations facing their clients, the staff had to be pragmatic in their interventions.

\section{A "Good" Family}

One case that PO Ananda dealt with involved a teenage mother who was 15 years and 8 months and her 23-year-old boyfriend. The hospital had reported her to the police on discovering she was underage when she had entered hospital to have her baby. The boyfriend was arrested by the police and charged with statutory rape and the girl was placed in a home for sexually abused girls along with the infant. PO Ananda was extremely unhappy with the outcome of this case. On visiting the girl's family as well as the boyfriend's family, his conclusion was that the law had been unnecessarily harsh in this instance. If the girl had been 4 months older, there would have been no case because both sets of parents had given their consent to or had accepted the relationship. Another factor that influenced PO Ananda's assessment of the case was that in his opinion, the girl's family was "not good". Inquiries from the gramasevaka (the local administrative officer) of the girl's village had revealed that her mother was a single mother currently in an "illicit" relationship, and that her father was in prison for having raped his sister-in-law. In contrast, PO Ananda thought 
the boy's family was a "good" family. The boyfriend had a job and the two had been living together with his family for some months. PO Ananda was in a quandary. While the girl's family had come forward to take the girl home, he was reluctant to let her go with her mother. The boyfriend too had requested PO Ananda to let the girl stay in the institution till she was old enough to get legally married to him rather than to let her go home to her mother. PO Ananda, although not happy about the girl being in the children's home, considering it unsuitable for her, could not let her return to the boyfriend's family unless they were married. In describing this case to me, PO Ananda at no point discussed the girl's wishes or her opinions. Instead, he had discussed with the boyfriend whether it might not be possible for him to arrange for her to run away from the institution and to live in hiding till she was of age to get married to him. However, this plan was rejected as too risky and the girl was left in the children's home until she was old enough to get married to her boyfriend. The baby in the meantime was handed over to the boy's family.

How POs arrived at the conclusions they did, and the ways in which they assessed risk or the best interests of their clients, were never quite clear to me. One factor that seemed to influence their decisions consistently was their assessment of the family unit. They often declared that protecting the family unit was one of their key objectives and said that they felt an immense sense of satisfaction when they were able to keep families together. Maybe PO Ananda felt that the family unit of the young girl, her boyfriend and child, although not recognised by the law, was a functional family that deserved his support. Families, when functioning properly, were viewed as the most appropriate unit in which children should be raised. Also, the main purpose of a family unit was seen as raising children. However, the staff also made decisions based on their opinion as to whether the child was being raised correctly within the family or if the family unit was appropriate. If they felt that the family was not doing a proper job, they had no hesitation in correcting them or if necessary removing the child from the family. The Chief $\mathrm{PO}$ in the province once discussed a case with me in which a teenage girl had been removed from the care of her stepfather (who had raised her since she was a baby) after the sudden death of her mother because the PO involved in the case had considered it inappropriate for a young girl to be living with a man who was not her biological father. According to the Chief PO, the many cases of sexual abuse of girls by their stepfathers had led most POs to be very suspicious of stepfathers.

On another occasion, the Probation Unit received an anonymous letter from a "concerned citizen" raising concerns about the activities of two sisters who were living together with their children. The POIC requested PO Ananda to conduct an investigation. The elder sister was a divorced woman with a child and her sister was also separated from her husband and raising her child on her own. The letter hinted that the women were engaged in "unlawful" and "immoral" activities though not specifying anything except to say that they presented a "moral danger" to the neighbourhood. PO Ananda came back from his investigations, which involved a visit to the house, saying that although there was no real evidence of any "immoral" activity, his instinct said that there was something not quite right in the house. When I pressed him for further details, he told me that there were three females (the two sisters and a friend) living in the house and the house had three bedrooms with attached bathrooms. According to PO Ananda, the three attached bathrooms were somewhat suspicious and suggested a "guest house" type arrangement, which in his mind could mean only one thing: that the house was in fact a brothel. Based on his suspicions, the two sisters were asked to come to the Probation Unit to make a statement. In making assessments as to what constituted a "proper" family unit, various factors were considered. Clearly, three single women raising children on their own did not constitute a proper family unit. Although PO Ananda took no further action because he had no evidence, he resolved to keep an eye on the household. 


\section{Sexual Propriety}

This extremely close surveillance of women's behaviour was also evident in the way that staff members handled complex cases of sexual abuse. In one instance where a teenage girl had been sexually abused by a teenage Buddhist monk in the local temple, PO Senani was shocked at the insouciance with which the girl had described what had happened to her. Her ability to articulate clearly and unselfconsciously the abuse that she had undergone made her "innocence" somewhat open to question. "These girls, nowadays; they can't even leave a Buddhist priest alone," said PO Senani at the end of the interview. The insinuation was that somehow the fault lay with the girl because she did not resist the advances of a man which, by virtue of his religious status, were so clearly taboo.

The future fate of these abused girls was considered pretty hopeless. Other than living a life of quiet confinement, the most that they could hope for was that they would be able to find a man who would overlook what had happened and marry them. In fact the POIC mentioned a couple of cases where she had actively helped the girls hide their past from future husbands by assisting them to find adoptive families for the babies or by placing the girls in children's homes. Once she advised a family who was taking a girl home who had been in an institution for sexually abused girls to make sure that the "truth" about the case was never revealed and to construct a story as to why the girl had been away from home for some time.

An incident that caught the attention of all those at the office and was the subject of intense discussion highlighted some of the attitudes that subtended the way sexually abused girls were viewed. It involved a budding romance between a boy and a girl from two children's homes. Each month, a young boy around 17 years old came to the Probation Unit with one of the staff members of the home in which he had been placed by the Probation Unit. He would come in the morning and sit on the bench at the entrance to the office and wait patiently till he was called to court. He was a good-looking boy with an air of confidence and assurance usually lacking in the other children who came to the Probation Unit. He was always very smartly and cleanly dressed in well-laundered blue jeans, a pale coloured shirt and sandals, in contrast to other children whose unkempt, rumpled looks always made it possible to identify them as children from institutions.

PO Ananda one day told me that the boy, whom I shall call Senaka, was the chief accused in a murder trial. A longstanding feud involving two families had culminated in the death of one person during a violent altercation. The fatal blow was supposed to have been dealt by Senaka, who had got involved because he tried to help his father who was being beaten by the murdered man. Senaka's whole family was behind bars as a result of this incident and Senaka had been in the children's home for some years now. The staff felt sorry for Senaka, saying he was a nice boy who had got into trouble because of his father.

One day, PO Mrs. Kularatne mentioned to the others that she noticed something "going on" between Senaka and one of the girls from a home for sexually abused girls. At a sports meet organised for children in institutions, PO Mrs. Kularatne had noticed that the girl had been unusually interested in the races in which Senaka had been participating and also that the two had seemed quite friendly with each other. The staff discussed the story sympathetically; after all, they were two attractive young people and it was inevitable that they should have some interest in each other, especially given the highly constrained environments in which they lived, which had limited opportunities for interaction with members of the opposite sex. However, PO Mrs. Kularatne was also of the opinion that the Matron of the girls' home should probably be a bit careful because this was bound to become a complicated affair. Wathsala, the Administration Officer, felt that this relationship might be an ideal solution for both young people given their histories and their current situations. "But someone should talk to the two of them. "Senaka may not know this girl's history," said the POIC. "There is no telling what will happen when he finds out". I inquired as to what part of the girl's story Senaka would find problematic. Given that he was probably 
already aware that she was in the girls' home because of sexual abuse I wasn't quite sure what the POIC was implying. Then the others raised the issue that the girl was no longer a virgin.

In the opinion of the POs, these were issues that caused problems in marriages because men expected their wives to be virgins at marriage. Although the girl was not to be "blamed" for her situation, virginity was considered a symbol of a woman's character and morality; the fact that she had lost her virginity through rape did not absolve her completely from having questions raised regarding her character and morals. "Senaka is a very impulsive person. How do we know what will happen when he finds out the 'truth' about the girl?" asked the POIC.

What emerged from this discussion was the view of at least some of the staff that the girl was in a far more socially ambiguous position than Senaka, who was involved in a murder trial. That the girl was somehow "damaged" and that this gave her fewer options in life was evident. In as much as being accused of murder seemed less problematic than having been a victim of rape, it seemed that although a victim of sexual abuse deserved sympathy, her chances of leading a normal life were quite slim, and the so-called rehabilitation process, if anything, reinforced the idea that the victim's life had changed irrevocably. Rape victims lost their purity and hence had to carry that stigma with them for the rest of their lives.

Over and over again, I was confronted with cases in the Probation Unit in which the response of the staff to the problems their clients faced seemed overwhelmingly inadequate. While the laws on rape and sexual abuse had been made tighter, the slowness of the judicial process meant that these cases dragged on for many years during which time the accused male was usually released on bail. On the other hand, a girl who had been subjected to rape or sexual assault either ended up in an institution or had to hide her shame from society. This meant that if the girl had been attending school, her schooling was disrupted. Most often, the girl was sent away from her home. Given that the staff felt that once something of this nature happened, there was not much the girl could do to recover her respectability and her virtue, the emphasis they placed on "protecting" girls was understandable. Parents and families were often berated for not providing adequate protection to girls; girls would be reprimanded for not protecting themselves adequately or for attracting male attention by dressing provocatively, going about unaccompanied or by behaving in a "forward" manner.

The staff had little hesitation in overruling the decisions and interests of the family, including parents, and insisting that the staff be allowed to decide what was in the best interests of the child, if they felt that the family was making wrong decisions on behalf of the child. In such situations, neither the wishes of the child nor those of the family were given much consideration. In these instances, even policy directions discouraging institutionalisation or their own discomfort with the quality of care in children's homes were not considered as the "protection" of girls was paramount. In another incident, when a mother who had placed her children in a children's home while she was employed in the Middle East, returned home on holiday and requested permission to take the children home for the duration of her visit, the POIC was firm:

You can visit the children, but you can't take them home. It will disrupt their education and disturb them emotionally. They will feel even lonelier after you leave them again (sankawahædei).

When discussing the case later, the POIC confided to me that the mother was not a "good" woman and that there were rumours in the village that she was having an affair while working in the Middle East. The POIC had made the decision that the children were better off in the children's home than with an "immoral" mother, even for a short time. Thus, in most instances, the Probation Unit staff made decisions that they felt were right, based on their assessment of the morality of the individuals concerned. The lower class position of the majority of clients at the Probation Unit meant that the inferior moral position 
associated with the "low class" coloured the decisions of the staff. The class difference also meant that clients were less able to challenge the staff. Since the majority of their clients were poor, this meant that the staff had considerable power over the lives of their clients.

\section{Being a "Proper" Woman}

While families and parents had the primary responsibility of protecting their children and maintaining the family unit in an appropriate manner, the primary responsibility for this rests on women. Women were expected to have the patience and strength to deal with whatever vicissitudes life dealt them. Characteristics such as impatience, intolerance and cruelty (napurukama) in women were often regarded as the main causes of many marital disputes, conflicts and problems with children.

Once when a violent argument erupted between an estranged husband and wife while they were in the Probation Unit, PO Mrs. Jayaweera was unsparing in her reprimands to the woman while explaining to her why the husband got angry:

Getting angry is a human failing. When you are a woman, you

must have great patience. When you scold like this, is it a surprise

that men become violent?

Women were expected to be able to put up with suffering and to tolerate the weaknesses and limitations of their husbands patiently. Even in situations of extreme abuse, women were expected to be able to rise above it all. Discussing a case of severe domestic violence that the Probation Unit had dealt with, PO Mrs. Jayaweera was unhappy that the wife had complained that the husband was attempting to return to the house after he had been released on bail. The case involved a man who had been so violent towards his wife and children that he had been beaten up by the men in the village who felt they could no longer tolerate his behaviour towards his family. The villagers had subsequently dragged him off to the police and the case came to the Probation Unit's attention because the woman needed a place to live with her young children. PO Mrs. Jayaweera was extremely active in finding a place for the woman to stay, calling upon her local NGO contacts to help the woman find accommodation and mobilising to find financial help for the family. In fact, she had visited the family regularly soon after they moved to their new accommodation and had even taken cooked food to them for a couple of days to help them settle. However, she had also advised the wife to give her husband another chance when the wife had complained that he had tried to come into the house in violation of the police order that he was not to contact the family. PO Mrs. Jayaweera felt that the wife owed it to the children to try to keep the family together. When I asked her if it was fair to ask the woman to take the man back, given how violent he had been with her, PO Mrs. Jayaweera, though agreeing that it would be difficult, said: "When you are a woman, you have to make many sacrifices for your children". Thus, although she was sympathetic to the woman, and had even gone out of her way to help the woman and her children, she was still reluctant to see the family break up. The idea that the woman might attempt to build an independent life for herself and her children was not wholly acceptable to PO Mrs. Jayaweera.

Not surprisingly, women who did seem to be able to keep the family together against all odds were viewed with much satisfaction and approval. One day a young couple walked rather timidly into the Probation Unit. Both looked as if they were in their early twenties and I thought they were siblings because they looked very much alike: tall, slim and dark. They walked up to PO Ananda who recognised them and greeted them with a smile. After talking a few minutes to him, he suggested they meet PO Mrs. Kularatne.

According to PO Ananda, who described the case to me, the man had first got into trouble for attempted rape when the woman was about 14 years old. Eventually the two had got married when she was old enough and they had a baby daughter. The woman found employment in the Middle East and left her husband and daughter in the care of her older 
sister while she was away. During this time, the man had started frequenting a house in the neighbourhood that sold 'kasippu'. PO Ananda said this household was a "bad" house; it was run by a couple and the woman was not of "good" character. PO Ananda said she "seduced" (pelambuwa) the young man who started an affair with her and eventually moved into that house with his baby daughter. PO Ananda said that the woman, in an attempt to cover up her relationship with the young man, which was causing problems between her and her husband, had pushed him into a relationship with her adopted daughter who was about 14 years of age at the time. Eventually both the mother and daughter became pregnant. Although the older woman claimed that her child was her husband's, evidently no one believed this. PO Ananda pointed out that the couple hadn't conceived before and had had to adopt a child; this suggested that the man was unable to have children. The situation had caused many problems in the household as well as total uproar in the village. Outraged villagers had written several petitions to the Probation Unit, demanding that some action be taken. Eventually, the young man had run away with the 14-year-old girl and was caught by the police and charged with statutory rape. PO Ananda, who was in charge of the case, said that at that time, the young man had said he wanted to separate from his wife and marry the younger girl. Mother and daughter had given birth in the same hospital around the same time and the girl was sent to a home for sexually-abused girls and her baby was placed in a home for infants. Subsequently, the girl had been allowed to leave the children's home and now lived with her adopted parents who had also taken her baby. The wife of the young man returned home from the Middle East after having being informed of all what had happened. The young man was eventually released on bail and had returned to his legal wife. They had now come to the Probation Unit to find out if there was a way of getting the charges against the man dropped or reduced because the charge of statutory rape would carry a long prison term if the man were found guilty. PO Ananda felt that the case at this point was getting beyond him and needed the intervention of a "mature" woman and had hence asked them to talk to PO Mrs. Kularatne.

The couple, who were clearly nervous, talked to PO Mrs. Kularatne for a long time. The girl sobbed while relating her story and her husband kept handing her bits of tissue to wipe her eyes. Watching the two of them, it seemed impossible to believe that such a drama had taken place in their lives. There did not seem to be any animosity or anger between them despite the harrowing situation in their lives. PO Mrs. Kularatne was very gentle with them both:

There is no use going over what happened in the past now. As a woman, you have shown exemplary qualities. You have shown great patience and tolerance. Your husband is lucky to have a wife like you.

She told the husband "not to do foolish things again" and to be careful in his new job as a waiter in a restaurant as he could be "tempted" again in such an environment. She also told them that the case would have to proceed but since the case was bound to drag on for some years, not to worry about it, but to try and lead a new life together happily. Opinion in the office was divided as to what the best advice was to be given to this couple. While everybody agreed that protecting the young family was important, the ability of the young man not to stray again was considered doubtful. However, the entire office agreed that his wife deserved all their respect and support although the POIC felt she was being foolish to trust her husband again.

The efforts of the staff at the Probation Unit to keep families together were not necessarily completely out of step with their clients' views of how things should be. In the case described above, the main concern of the young wife had been to ensure that her husband was kept out of jail. Her resolution to overlook her husband's transgressions and to attempt to keep her family together won her the approval and the sympathy of the staff at the 
Probation Unit. The older woman who had "seduced" the young man and also "pushed" him on her adopted daughter was cast as the villainess in the story. The young man was viewed merely as foolish and weak.

\section{Legal versus Moral Solutions}

The law in cases of sexual abuse and rape focuses on identifying and prosecuting the guilty party. In contrast, the Probation Unit got involved in the lives of the victims and inevitably found that the guilty parties were an integral part of their victims' lives. While the law took a quite straightforward position on the apportioning of guilt and victimhood, this was not quite so simple for the staff at the Probation Unit. As described above, the lives of their clients were extremely complicated and the simple categories that are part of the legal approach to problems were hardly adequate to comprehend these complexities. At the same time, the Probation Unit was wholly under-resourced to provide the kind of support that these clients needed. In many ways, therefore, assessing the cases before them from a moral standpoint was the most pragmatic option available to the staff. This allowed them to apportion blame and, in some ways, even accommodate the complexities of the situations that they were presented with in a way that the existing legal framework was unable to do.

The fact that the framework that the staff at the Probation Unit used to apportion blame was based on a set of values based on ideas of family, of respectability and the behaviour and demeanour of women inevitably meant that the outcomes of those decisions were harsher for women and girls. But, as we have seen, because the legal process is implemented in a situation where there are no resources or systems to support the consequences of the legal decisions, the law - even though it is explicitly drafted to protect the vulnerable - does not necessarily provide better outcomes for those involved.

The difficulties that the Probation Unit staff faced meant that they were also deeply frustrated by their inability to respond adequately either in terms of the law or their own moral frameworks. Sometimes their clients suffered the brunt of this frustration in ways that often seemed insensitive and harsh. Once, for example, PO Senani, dealing with an elderly woman, snapped loudly at her:

Stop bothering us. There is nothing more I can do. Your daughter goes here and there (athana methane gihilla) and gets herself abused. We can't just do things the way she wants.

As the details of the case became clearer, it turned out that the woman's daughter, who was blind, had been raped by a man from their village when she was 16 years of age. The accused had been in remand for the last 5 years and had recently been released. The family had been unable or unwilling to keep the girl at home after the incident. Because the girl was 16 years at the time, she was too old to be placed in a children's home. The only place that had been available to accommodate her had been a Detention Centre for girls. The girl had been beaten by the staff at the Detention Centre for some misdemeanour and had subsequently been transferred to a Rehabilitation Centre for sex workers. PO Senani said that the girl had been abused there by the other inmates and had refused to remain in the Rehabilitation Centre. From the Rehabilitation Centre, she was transferred to an old people's home from which she had run away. She had again been abused by a man who had "befriended" her when she had run away. She had been picked up by the police when she was wandering on the streets and had been admitted to hospital where she had been for the last two weeks. Her mother was still reluctant to take her home and the girl was refusing to return to the old people's home. PO Senani was in a quandary as she had no other place where the girl could be sent. She agreed that the old people's home was hardly a suitable place for a young girl, but the only other option was to send her to her own home, an option that her mother refused, saying that she was too old to take care of her. This was when PO Senani snapped at the mother and finally persuaded her to take the girl back home. No one 
was happy with this solution and PO Senani was aware that it was likely to be only a temporary solution.

\section{A Time of Godlessness}

Dealing with cases like those I have described on a daily basis drained the staff and frequent remarks were made regarding the vileness of men, the depravity of the times and the difficulties of their job. The senior staff talked longingly of the past when the "crimes" for which their clients required rehabilitation were relatively simple ones such as robbery or truancy. PO Mrs. Jayaweera often said that the kind of incidents that they had to deal with in the present only happen during 'abuddassakala' (unholy periods of time when all rules and conventions are broken) and warned the unmarried people in the office not to become cynical about marriage and family life after seeing these cases. Most amazingly, despite all evidence blowing apart the myths of caring and strongly-knit families and the supposedly traditional values of Sri Lankan society, families and traditional values were still regarded as the main strengths of Sri Lankan society, ones that distinguished it from the sexual promiscuity of the West. Once discussing a rumour that a colleague's son had married a foreigner, PO Mrs.Kularatne was appalled: "Don't know what kind of sicknesses these women have. In those countries, parents start giving girls contraceptives the moment they attain puberty". Similarly, when a voluntary children's home wanted to take the children on a holiday to the seaside, the Commissioner had given permission on the condition that a PO accompany them and had nominated PO Mrs. Jayaweera for the trip but she was seriously displeased:

The beach is not a suitable place to take these children. It's full of half-naked white women (suddi), wearing nothing more than underwear. I once went to the beach and I was so ashamed I didn't know where to look. The management of this home want to satisfy their own perversions and they are using the children as an excuse. I am going to tell the Commissioner that this is inappropriate and I will not go.

Once discussing the issue of morality and culture, PO Ananda had this to say:

Our culture is different to that of the West. Our laws are different.

Here families stay together. There is less sexual misconduct, not

like in other countries. But sometimes suppression leads to

frustration and then people engage in perverted behaviour. Girls

have to be sociable but they also have to know how to protect themselves.

While deploring the human tragedies unfolding in the Probation Unit on a daily basis and seeing the moral decay and the deterioration of cherished values, the staff were yet able to maintain a belief in the dichotomy of a spiritually bankrupt West and a spiritually superior East. The threat to Eastern culture was still seen as principally from the decadent influence of the West. One way in which they were able to maintain this belief was by distancing themselves from the moral decay and decadence of the times. This distancing was also commensurate with the "in-between" class position occupied by the Probation Unit staff. These things happened only to those who were too ignorant, uneducated and foolish to know better (their class inferiors) or to those whose lifestyles had been corrupted through exposure to and imitation of Western culture (usually their class superiors). Since the vast majority of their clients were poor and forced to submit to the machinations of the legal and state structures, this provided the Probation Unit staff with opportunities to stamp their moral authority on them. The immorality and decadence of their class others on either side could only be stemmed through inculcating in them respect for traditional values, instilling a 
sense of pride in local culture and way of life. Given the extent to which the staff engaged in correcting the morals of their clients or instilling ideas about what was considered good and respectable behaviour, it is possible they believed that the mantle of Anagarika Dharmapala had fallen on their shoulders. In fact, the staff's analysis of the state of modern society suggested that they believed that Sinhala Buddhist culture was as much under threat today from the corrupting influences of the West and its local agents as it was during Anagarika Dharmapala's own time. As during Anagarika Dharmapala's time, this moral ideology was juxtaposed with ideas of modernity in which certain practices and technologies of modernity were fully accepted. Just as Dharmapala's Gihi Vinaya ["Code for the Laity"] included rules about sanitation, cleanliness and the use of the fork and spoon, and Piyadasa Sirisena's heroes and heroines were educated in English and well versed in European literature, the ideal modern parent and especially the modern mother, according to the staff of the Probation Unit, is not only a moral person, but also a mother who immunised her children on schedule, supervised their homework and nutrition, took care of their health, provided them with the opportunities to become familiar with modern technology, and provided them with extra classes in English. At the same time, she ensured a childhood of innocence and purity. A good child was one who was both academically successful and moral and a good parent was one who ensured that. Explaining and understanding the tragedies that unfolded daily at the Probation Unit through this framework meant that the staff could intervene from a position of moral authority and even superiority. In the process, they were also asserting the values and norms that they believed distinguished them and rendered them superior to their class others.

\section{Moral Breakdowns, Ambiguity and the Middle Class}

What I have endeavoured to show in this paper is how Probation Unit staff drew upon a particular morality when dealing with clients. I have explored this morality specifically in terms of its disposition towards women and girls. As discussed, this morality stressed the virtues and respectability of women as defining the stability and happiness of the family and, by extension, society and the nation. The family and the home was the main unit which the Probation Unit staff sought to protect; their assessments of what to do with their clients were arrived at in relation to what would be the best for the family or, alternatively, if the family was considered inadequate, how those under the Probation Unit's care could best be protected from that family. These deliberations were undertaken while reflecting on the moral issues that were at stake in each instance. This is where the respectability and virtue of women and girls were crucially important.

How nationalist representations of women have been shaped by patriarchal relations of power and simultaneously reproduce those relations has been well documented by feminist scholars in Sri Lanka (see for instance, De Alwis 1995, 1997; De Mel 2001). My efforts to theorise this in terms of morality point towards how reproducing gendered power relations also can serve as a means of articulating class identities.

By using morality as a framework for dealing with clients, the Probation Unit staff members were also constructing and displaying their own social identities as members of the middle class. The ambiguities of their class position and their efforts to differentiate themselves from the lower classes as well as the upper classes meant that their moral position had to be constantly articulated and re-presented. The ambiguity of their position was compounded by the paucity of resources at their disposal to deal effectively with the complexities of their clients' lives and experiences and to thus maintain their professional status and credibility. Often required to implement court decisions that did not allow for complexities, the Probation Unit staff resorted to moral frameworks to respond to their clients' problems. In doing so, they were also then able to assert their own moral positions, as well as their own virtue and respectability, which was so necessary for maintaining their positions in society. 
These are not merely moments of "ethical breakdowns" as Zigon (2007) has termed them, but representative of the ambiguity of Probation Unit staff's social position and professional status as well as their own struggles to explain the complex lived experiences of their clients. Interestingly, the work that went into making oneself "morally appropriate" or "socially acceptable" (Zigon 2007:261) was not through working on oneself, but rather by making public judgements about others. The morality in the Probation Unit was articulated in terms of a public discourse that constructed a shared moral space. The inclusion or the exclusion in this shared moral space was what determined a person's cultural identity and social acceptability. Thus, for the Probation Unit staff, the shared moral space was also a shared cultural space. The narratives they drew on to construct this moral space were to be found in ideas of Sinhala nationalism, with its roots in various attempts to articulate a distinct social and cultural identity particularly in relation to the English educated, Westernised elites.

\section{References}

Amunugama, Sarath. (1997). "Ideology and Class Interest in One of Piyadasa Sirisena's Novels. The New Image of the 'Sinhala Buddhist' Nationalist" in

Michael Roberts (ed), Sri Lanka. Collective Identities Revisited. Vol 1. Colombo: Marga Institute.

de Alwis, Malathi. (1995). "Gender, politics and the 'Respectable Lady'” in Pradeep Jeganathan and Quadri Ismail (eds), Unmaking the Nation: The Politics of Identity and History in Modern Sri Lanka. Colombo: Social Scientists Association.

Chatterjee, Partha. (1989). "The Nationalist Resolution of the Women's Question" in Kumkum Sangari and Sudesh Vaid (eds), Recasting Women. New Delhi: Kali for Women.

Chatterjee, Partha. (1993). The Nation and its Fragments: Colonial and Postcolonial Histories. Princeton, New Jersey: Princeton University Press.

de Alwis, Malathi. (1997). “The production and embodiment of Respectability: Gendered demeanours in Colonial Ceylon" in Michael Roberts (ed), Sri Lanka: Collective Identities Revisited Volume 1. Colombo: Marga Institute.

de Mel, Neloufer. (2001). Women and the Nation's Narrative: Gender and Nationalism in Twentieth Century Sri Lanka. Maryland: Rowman and Littlefield Publishers, Inc.

Foucault, Michel. (2000) in P. Rabinow (Ed) Essential Works of Michel Foucault, Vol 1: Ethics: Subjectivity and Truth. London: Allen Lane.

Laidlaw, James. (2002). "For an Anthropology of Ethics and Freedom" Journal of The Anthropological Institute. 18 (2): 311-32.

Liechty, Mark. (2002). Suitably modern: making middle class culture in a new consumer society. Princeton, N.J: Princeton University Press.

Ministry of Youth Affairs. (2006). National Action Plan for Youth Employment in Sri Lanka. Colombo: Youth Employment Network (YEN) Secretariat.

Obeyesekere, Gananath. (1997). "The vicissitudes of Sinhala-Buddhist Identity through Time and Change" in Michael Roberts (ed), Sri Lanka: Collective Identities Revisited Volume 1. Colombo: Marga Institute.

Robbins, Joel. (2007). “Between Reproduction and Freedom: Morality, Value and Radical Cultural Change" Ethnos 72 (3): 293-314.

Wickramasinghe, Nira. (2006). Sri Lanka in the Modern Age: A History of Contested Identities. London: Hurst and Company.

Zigon, Jarrett. (2007). “Moral Breakdown and the Ethical Demand: A Theoretical Framework for an Anthropology of Moralities" Anthropological Theory, 7 (2):131-50. 
Zigon, Jarrett. (2009). “Within a Range of Possibilities: Morality and Ethics in Social Life" Ethnos 74 (2): 251-276

Harini Amarasuriya, Open University of Sri Lanka 